\title{
Study on Party Newspaper International News Report Strategy of Maritime Rights and Interests Disputes
}

\author{
Chen Long \\ School of Marxism,Tianjin University Of Commerce,Tianjin300134 \\ 39261894@163.com
}

Keywords: People's Daily, the dispute about Diaoyu Islands between China and Japan, maritime rights and interests, party newspaper, international news report strategy

\begin{abstract}
As far as the survival and development of a country, especially the coastal countries, are concerned, maritime rights and interests are crucial. Nowadays under the economic globalization and information globalization, the maintenance of China's maritime rights and interests not only needs to speed up the increase of economic and military strength, but also urgently needs to optimize communication means and improve propaganda art. How the party newspaper can improve the international news report strategy and raise the ability of international public opinion guidance become the topic of maintaining China's maritime rights and interests. Taking the reports of the dispute about Diaoyu Islands between China and Japan in People's Daily as the samples, we analyze the public opinion guiding framework implied in the reports of the dispute about Diaoyu Islands between China and Japan in People's Daily in the paper. What's more, based on this, we put forward the international news report strategy of party newspaper in the disputes of maritime rights and interests in the paper.
\end{abstract}

\section{Introduction}

The dispute about Diaoyu Islands between China and Japan is developing and changing. However, China's news communication enterprise, especially the news reports of party newspaper, is also evolving and changing. Compared with the former situation, when China's party newspaper refers to the news reports about the maritime rights and interests of a country, it will pay more attention to the communication mode and communication effect so as to raise the ability of public opinion guidance better. When China's party newspaper has reported the dispute about Diaoyu Islands between China and Japan these years, a set of basic "report framework" has been formed. What's more, with this "framework" China's position and attitude can be expressed and the public opinions at home and abroad can be actively guided.

\section{The Connotation of Maritime Rights and Interests}

The maritime rights and interests of a country include the maritime rights and the maritime interests of this country. The maritime rights and interests not only belong to the state sovereignty, but also the important content in the category of the state sovereignty's derived rights. What's more, it is also a kind of right which is formed by the national territory extending in the direction of ocean. In other words, Maritime rights and interests are the rights gained from the ocean by the state and some rights derived from this. Usually these rights have the sovereign nature.

Because the marine rights and interests have involved resource, traffic, scientific research and 
other aspects, various countries and regions in the world pay more and more attention to their own marine rights and interests. Internationally, even though we have the United Nations Convention on the Law of the Sea as the legal basis of judging and dealing with the problems, many countries still have the conflicts about the sea borders, the island's sovereignty and other aspects. It is reported that more than 380 ocean borders among the countries with the adjacent or opposite coasts need to be divided. However, the demarcation which is truly realized only accounts for about one-third.As the forces of various countries extend towards the ocean, the ocean becomes huge political and economic focus. It leads to that about 60 countries in the world have the disputes related to the islands.

\section{Macro Framework Analysis of the Dispute Reports about Diaoyu Islands between China and Japan in People's Daily}

In the content, production, effect and other three major fields studied by the media, the number of research literatures about the framework analysis on the text content is the maximum. And "the proportion of content analysis is as high as 61.5\%". The premise of framework theory's content analysis is that we must admit different expression can lead to different communication effect and conscious behavior. That is to say, different frameworks expression means can produce different effects. Before we adopt the frame theory to study the text we need to explain several aspects. First, News framework is the certain principles which the media process the news facts selectively. These principles are derived from the position of media, editorial policy and interest relationship related to the events. At the same time, News framework is also restricted by the news value and other special laws. These laws determine the basic attitude and essential judgment held by a medium on large and small complicated news events. That is the communicator's framework which is often said by people. As far as People's Daily is concerned, when it reports the dispute about Diaoyu Islands between China and Japan, the position of "First Party Newspaper" determines that it can firmly safeguard China's maritime rights and interests, and the purpose of all reports is to maintain the country's core interests.

\section{The Use Framework Analysis of News Genre}

According to the above analysis, we can obtain the framework of the reports about Diaoyu Islands between China and Japan in People's Daily on the use of news genre. Thus, we can deduce the report framework of People's Daily in the process of safeguarding national Marine rights and interests.

The Messages and Remarks, the Two Kinds of Genres as the Main. When People's Daily reports the events involved the safeguard of national Marine rights and interests, it is more inclined to messages and remarks to guide public opinion. In the message, if we can timely follow up the events development, it not only can reflect Japan's behavior but also can report our response and retaliatory action more timely. Thus, we can pay attention to the adjustment of report issues and report objects. The remarks show that China's position against Japan's behavior, especially the "Guo Jiping's" remarks with the strongest influence is enabled to use. A large number of remarks with more than ten thousands words in total whose names are respectively How can China's Diaoyu Island permit others to "buy and sell" wantonly and The diaoyu islands is Chinese territory, and it is an irrefutable evidence! are published in the high-tide period of events. This fully embodies the powerful public opinion offensive of People's Daily at this stage.

Other Genres as the Supplement. Seen from the point of quantity and strength, the messages 
and the remarks can be called to be the "cannon" on the public opinion battlefield of Diaoyu Island in People’s Daily. The roles of other genres play are "submachine gun”, “revolver”, and "rifle”. In the explanatory reports and review reports, the contents with explanation and analysis are the viewpoints with the authors' subjective reviews mostly. Documentary communication adopts a large number of historical materials to be as the evidence. The interviews records interview the government spokesman or experts and scholars directly. The four kinds of genres have rather strong "mortality", and they belong to the genre of "submachine gun". If we combine them together, they will have stronger strength. News features and photo news pay more attention to the readers' feelings. The lyric composition is much thicker, so they play the role of "revolver". For the occurrence of the dispute between China and Japan, the articles, including literary works, documents and other genres find new themes. The frequency-of-occurrence of poetry, prose and other literature works related to the Diaoyu Islands rapidly increases. It unconsciously influences the public opinion guide.

The Positive Correlation between Report Frequency and Events Development. As a whole, the quantity change and report frequency of the dispute about the Diaoyu Islands between China and Japan and events development are positively correlated. Especially the key genre, the quantity change and report frequency at each stage are consistent with the events development. As the official Communist newspaper, based on the interests of the state, the responsibility and mission given by People's Daily give the positive and effective voice and indicate the solemn position that "the sovereignty of Diaoyu Islands belongs to me" so as to effectively guide the public opinion at home and abroad. In the page layout of People's Daily the quantity change of some genres and the overall situation are not the same. Then, through a reverse reasoning we can get that the role of these genres in public opinion guide is not crucial, and under the premise of less report quantity the arbitrariness of distribution is much bigger.

\section{The International News Report Strategy of Party Newspaper in the Dispute about Maritime Rights and Interests}

As a discipline the international communication enters China in the early 1980s. Compared with western countries, it starts relatively late. A large part of its contents embody in the international news reports of China's mainstream media. Under this background, the international news propaganda of party newspaper meets new challenges - to speed up the improvement and optimization of international news report strategy and help our country to maintain the national marine rights and interests.

These strategies pay attention to the use of advanced concept and operation rule as well as the unique skill of public opinion guide so as that the audiences get the conclusion by the report and guide of news events. In addition, we should combine the rational content with the emotional language expression so as to win the audience's attention at home and abroad actively and effectively. Specifically, these strategies can be reflected in six aspects. First, dig the news fact deep and learn to "speak with facts" truly. Second, strengthen "the agenda setting" and change "the passive coping” into guide actively. Third, grasp the report framework scientifically and cooperate with national diplomatic measures. Fourth, use the international public opinion opportunely and achieve to "make force from a borrowed force". Fifth, get through "two public opinion fields" and form a multi-level and comprehensive communication pattern. Sixth, adhere to "opening doors and running newspapers” and strengthen its communication with foreign countries.

Dig the news fact deep and learn to "speak with facts" truly.Based on the framework which has been owned by the party newspaper, and under the premise of not changing its use tendency on 
news genre, if we want to improve the communication capacity and influence of news report, we must start from the micro and reasonably change the reports mode of objective news to let the factual report to "speak with facts" truly.

News is the art of "speaking with facts". Before we discuss how to "speak with facts", the author first want to clarify a set of arguments whether "speaking with facts" is news writing law or not.

Strengthen "the agenda setting" and change "the passive coping" into guide actively.In the dispute between China and Japan, New York Times makes the whole event be built into another picture. The newspaper argues the reason for the outburst of the Diaoyu Islands dispute is that it originates from the expansion of the Chinese political ambitions. China uses the country's growing economic strength to threat to Japan so as to force Japan to hand over the territorial sovereignty of Diaoyu Islands. Similarly, Germany's three mainstream media's reports about the dispute event of Diaoyu Island between China and Japan, such as Le Monde, The Times and Spiegel, tell us the message that they "pay much attention to China and the judgment about the island dispute is unfair, and this is closely linked with the German prejudice against Chinese ideology and the mentality unbalance of China's rise. Comparatively speaking, People's Daily and other China's mainstream media appear weak in the international public opinion field so that it is difficult to form the substantial influence. Forced by the pressure from foreign media, we demand the party newspaper to strengthen "the agenda setting" when report the grand theme so as to change the passive response to active guide.

Grasp the report framework scientifically and cooperate with national diplomatic measures. Even though the news report can influence the public opinion communication effect from the number and strength, the report framework throughout the entire event is the key to obtain better communication effect."Speaking with facts" and strengthening "the agenda setting” mentioned above start from the microcosmic angle more. In individual level it requires each key "dot" and each important detail in the news report. The author puts forward that grasping report framework is to emphasize "the overall situation consciousness" on the basis of doing the specific reports well. We should grasp the macro report framework of the news agenda well to make a strong, stable and reliable report framework for specific facts. In a word, when the party newspaper and other mainstream media report the dispute events about Marine rights and interests, they should grasp the opening, developing, changing and concluding, and strong or weak nodes so as to make the whole report stage distinct, and make a distinction between the important and the lesser one, and present the rhythm aesthetic feeling of the ups and downs, and constant climaxes.

\section{References}

[1]Jia Yu. Delimitation of Maritime boundary must be fair. Global Times, 2004-07-21 (16) .

[]Jia Yu. Delimitation of Maritime boundary must be fair. Global Times, 2004-07-21 (16) .

[2]Li Haibo. Find out the ghost: concept and identification methods of news text frame [master's degree thesis]. Kunming: Yunnan University, 2013. 13.

[3]Guo Qingguang. Communication tutorial. Beijing: Chinese People's University Press , 2011.P209.

[4] Xu Ning. The New York times, the tendency research on the Diaoyu Islands events report in 2012 [master's thesis].Guangzhou: Ji'nan University,2013.30. 
[5]Li Danna. The report analysis of German media towards the Diaoyu Islands events between China and Japan__Based on the viewpoint of framework theory. College Newspaper of Human Administration College, 2014,(3):125. 